\title{
Die anthropologische Ästhetik Arnold Gehlens und Helmuth Plessners
}

\author{
Entlastung der Kunst und Kunst der Entlastung
}

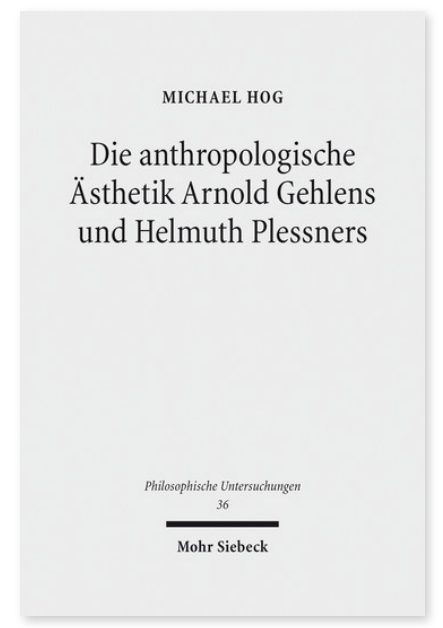

2015. VIII, 263 Seiten. PhU 36

ISBN 978-3-16-153716-5

DOI 10.1628/978-3-16-153716-5

eBook PDF 79,00€

ISBN 978-3-16-153559-8

Leinen $79,00 €$
Seit dem 18. Jahrhundert gibt es zahlreiche theoretische Versuche, Ästhetik und Kunst als Wesensmerkmale des Menschen auszuweisen. Aber erst mit der Entwicklung der modernen philosophischen Anthropologie im 20. Jahrhundert gelang es, philosophische, soziologische und naturwissenschaftliche Aspekte zu einem überzeugenden Gesamtkonzept zu verknüpfen. Dabei sind erstaunlicherweise die einschlägigen Reflexionen der beiden profiliertesten Vertreter der philosophischen Anthropologie, Arnold Gehlens und Helmuth Plessners, bisher kaum zur Kenntnis genommen worden, obwohl sie sich zeitlebens mit ästhetischen und kunstgeschichtlichen Fragen beschäftigt haben. Michael Hog untersucht die beiden Gesamtwerke nach Möglichkeiten und Grenzen einer anthropologischen Ästhetik und ästhetischen Anthropologie sowie ihren Implikationen für die moderne Kunst bis zur Gegenwart. Dabei liefert er die erste umfassende Analyse von Gehlens kunstsoziologischem Hauptwerk »Die Zeit-Bilder. Zur Soziologie und Ästhetik der modernen Malerei«, das die Entwicklung der modernen Kunst ebenso scharfsinnig wie weitsichtig beleuchtet.

Michael Hog Geboren 1977; 1998-2005 Studium der Philosophie und Germanistik; 2013 Promotion im Fach Philosophie; seit 2013 Abteilungsleiter und Studienrat für Philosophie und Deutsch an der Freien Schule Anne-Sophie Berlin.

Jetzt bestellen:

https://mohrsiebeck.com/buch/die-anthropologische-aesthetik-arnold-gehlens-und-helmuth-plessners-9783161537165? no_cache=1

order@mohrsiebeck.com

Telefon: +49 (0)7071-923-17

Telefax: +49 (0)7071-51104 